\title{
Erratum: Control of synaptic strength and timing by the release-site $\mathrm{Ca}^{2+}$ signal
}

Johann H Bollmann \& Bert Sakmann

Nat. Neurosci. 8, 426-434 (2005).

In the published version of this article, the labels were missing from the scale bars in Figure 2a. Panels a-c are reproduced correctly below.

a

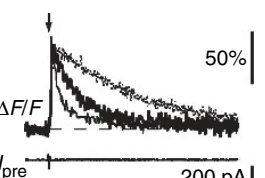

b

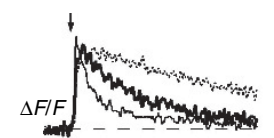

$200 \mathrm{pAl}$
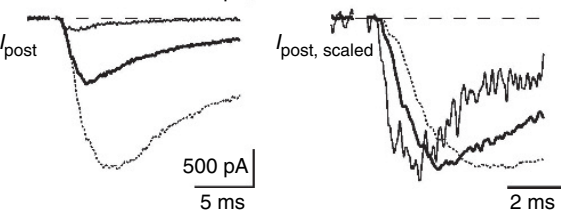

c
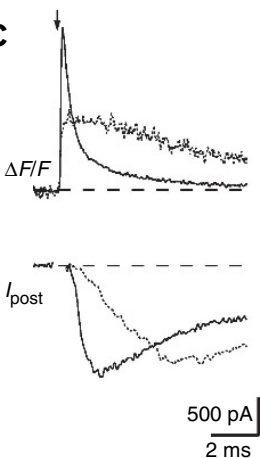

(a) Three $\Delta \mathrm{F} / \mathrm{F}$ transients and evoked EPSCs (/post), from three experiments (thin traces, thick traces and dotted traces, respectively). Arrow indicates time of UV pulse. To reduce postsynaptic receptor desensitization, cyclothiazide (CTZ) was added to the bath, which prolongs the rise time of EPSCs. The $\left[\mathrm{Ca}^{2+}\right]$ transient did not evoke measurable presynaptic currents $\left(I_{\text {pre }}\right)$. Electrical artifact in /post removed for clarity. (b) Same traces as in a, with EPSCs normalized to their peak amplitude. (c) Two $\Delta \mathrm{F} / \mathrm{F}$ transients of different amplitude and evoked EPSCs, from two different cell pairs.

\section{Erratum: Instructive signals for motor learning from visual cortical area MT}

Megan R Carey, Javier F Medina \& Stephen G Lisberger

Nat. Neurosci. 8, 813-819 (2005).

The upper trace in the right panel of Figure $\mathbf{2 b}$ on page 814 was mislabeled as ' $250 \mathrm{~ms}$ ', when it should have read ' $200 \mathrm{~ms}$ '. The corrected figure is below.

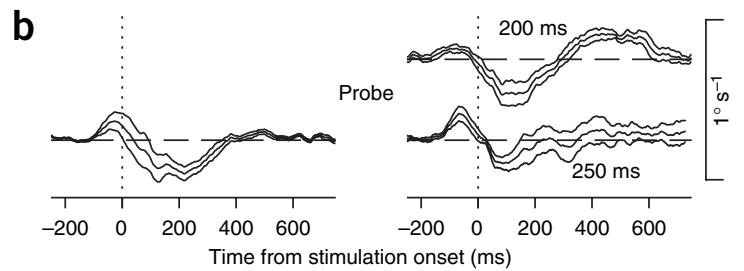

(b) Time course of learned eye movements ( \pm s.e.m.) along the learning axis, measured in infrequent probe trials. Microstimulation started $200 \mathrm{~ms}$ after the onset of target motion in Monkey Q and either 200 or 250 ms after the onset of target motion for Monkey E. Data in $\mathbf{a}$ and $\mathbf{b}$ are averages across experimental days ( $n=30$ for Monkey $Q, n=6$ for each temporal interval for Monkey E). 